\title{
of Desborde emocional y ficción ética en las novelas centroamericanas' de guerrilleros
}

\author{
Héctor $M$. Leyva
}

Universidad Nacional Autónoma de Honduras

Resumen: El presente ensayo revisa una serie de novelas centroamericanas de las décadas de 1960 a 1980, especialmente Pobrecito poeta que era yo... de Roque Dalton. El análisis parte de la premisa planteada por Brian Massumi de que los encuentros, los choques, los roces de los cuerpos (en este caso implicados en la violencia revolucionaria) desencadenan corrientes emotivas e intelectivas siempre en trance de ser atrapadas por las rejillas semánticas de las ideologías. Lo que se conecta con los planteamientos de Judith Butler sobre el giro auto reflexivo que construye al sujeto en su apego a un poder normativo. Se intentará mostrar de qué modo las novelas permiten reconocer un desborde emocional en el roce con las realidades sociales y los modelos de eticidad revolucionaria en que fueron capturados y que contribuyeron a la conformación del guerrillero como figura heroica.

Abstract: The following essay explores a series of Central American novels from the 1960s to the 1980s, especially Pobrecito poeta que era yo... de Roque Dalton. The analysis begins with the premise exposed by Brian Massumi which sustains that when bodies encounter, collide and rub with each other they unleash emotive and intellective currents that are prone to be captured by the semantic grids of ideologies. This assertion is close to that of Judith Butler about the selfreflective turn which constitutes the subject in its attachment to a normative power. The essay would attempt to show the mode in which these novels allow to recognize an emotional overflow in contact with social realities and models of revolutionary ethics by which they were captured and helped to conform the guerrillero as heroic figure.

Palabras clave: Literatura centroamericana, novela centroamericana, subjetividad, ética, revolución, ideología.

Keywords: Central American literature, Central American novel, subjectivity, ethics, revolution, ideology. 
Si el ser no fuera imperecedero, el "yo" de que escribo se habría destruido hace mucho. A unos puede parecerles una invención, pero todo lo que imagino que ha sucedido, sucedió en realidad por lo menos a mí. La historia puede negarlo ya que no he desempeñado ningún papel en la historia de mi pueblo, pero aunque sea parcial, rencoroso, malévolo, aun cuando yo sea un embustero y un envenenador, es a pesar de todo, la verdad, y tendrán que tragársela.

Henry Miller, epígrafe del capítulo "Mario. La destrucción" de la novela de Roque Dalton, Pobrecito poeta que era yo... (1971)

En un primer análisis de las novelas de guerrilleros centroamericanas sostuvimos que un elemento importante de su trama era la conversión revolucionaria, el proceso intelectual y afectivo que llevaba a los personajes a abrazar el compromiso (Leyva, 1996). Esto era algo que se derivaba directamente de la lectura de los textos que ofrecían más una escenificación de los dramas internos que el recuento de los hechos externos de las luchas. Esta observación conectaba con un alegato dentro de la historiografía, en el cual distintos autores destacaban que había sido determinante el momento de la conciencia para el desencadenamiento de las conflagraciones en contra de la idea de que éstas hubieran sido el resultado de una reacción automática, determinista de las condiciones sociales. En efecto, las novelas mostraban la radicalización de jóvenes de clase media, acicateados por sus lecturas y por sus sensibilidades en el contexto de injusticia y autoritarismo de las sociedades. No habían sido los más pobres los que primero se habían lanzado a la lucha armada como no habían sido las condiciones de mayor postración económica las que habían estado detrás de estos procesos. Por el contrario, las luchas pudieron ser el resultado no esperado de un aumento del dinamismo social, económico y cultural de las sociedades que en las décadas de 1960 y 1970 habían experimentado altos ritmos de crecimiento y habían conducido a la emergencia y engrosamiento de las clases medias, esas clases de las que provendrían los cuadros de vanguardia de las organizaciones político-militares revolucionarias.

En un segundo momento, una relectura de estas novelas nos llevó a destacar la centralidad del giro ético que podía reconocerse tras el proceso de conversión revolucionaria que exhibían los personajes guerrilleros (Leyva, s.f). Siguiendo las observaciones de Judith Butler 
(The Psychic Life of Power, 1997) respecto del carácter auto reflexivo de toma de conciencia del sujeto que en un momento dado reconoce y se adhiere a una norma que le permite construir su yo y hacerse visible socialmente (si bien esta adherencia, este apego, supone la rendición del individuo a una forma de poder), mostramos de qué manera en estas novelas la conversión de los jóvenes en combatientes escenificaba el momento turbulento de adhesión al paradigma ético revolucionario, el cual por una parte suponía la entrega a la lucha por la justicia social y por otro el sacrificio de la propia individualidad. Los jóvenes se mostraban en estas novelas en el momento de fundirse en el crisol de la revolución, respondían al llamado al compromiso, construían su visibilidad como sujetos (incluso como héroes) en la ética de la responsabilidad social, aunque experimentaban en el mismo momento una crisis, crisis del orden seguro y de comodidades de su condición social y crisis de poner en riesgo sus propias vidas.

Esta lectura, que en cierto modo se continúa en este ensayo, se relaciona con el propósito de elevar a la consideración la dimensión ética y emocional de la literatura y de ese momento histórico particular. En línea con las reflexiones sobre las narrativas del yo que van de la crítica literaria internacional a la centroamericana, de Paul de Man a Ileana Rodríguez y de Martha
Nussbaum a Arturo Arias, aquí se considera a la literatura directamente implicada en la construcción de modelos de vida para los individuos más que en la simple representación de realidades externas. Si la búsqueda del estilo puede ser una de las motivaciones de la escritura literaria, el orden expresivo buscado puede no solamente ser rítmico verbal o de tópicos argumentales sino de modos de sensibilidad y de trayectorias.

A la vista de los cambios notorios en los registros de la narrativa centroamericana en las últimas décadas, que ha llevado a la crítica a hablar de una literatura pospolítica, este tipo de reflexiones pueden contribuir a un mejor entendimiento de los cambios. El análisis de las novelas de guerrilleros muestra que la demanda de la lucha armada se encontró en el vértice del paradigma ético revolucionario por el que fueron reclamados los individuos. Una lucha armada inspirada por el modelo guevarista de un "hombre nuevo" y de guerra de guerrillas que suponía el sacrificio de la vida (de la vida social y de la vida del cuerpo) que fue distintivo de este momento y que pudo ser determinante en el sentimiento de crisis que trasuntan las novelas. En términos de Judith Butler, podría decirse que tal demanda muestra los perfiles de un poder sacrificial tras el paradigma ético revolucionario ejerciendo una influencia traumática sobre 
las sensibilidades de los jóvenes. por la crítica. Las contribuciones de Concluido este momento con los las recientes reflexiones sobre las acuerdos de paz que desactivaron los conflictos armados, esa particular construcción normativa ha podido disiparse, si bien es posible que la lucha social continúe en otros espacios, en otros frentes y con referencia a otros modelos de eticidad. Más que el abandono de la política, la nueva narrativa podría simplemente estarla replanteando de otra forma.

Este ensayo vuelve a leer las novelas de guerrilleros ahora con el interés de explorar el tránsito de la emoción a la norma ética que desde el primer momento fue registrado por los narradores y que, sin embargo, pudo no ser reconocido

emociones, especialmente en la obra de Brian Massumi (Parables of the Virtual, 2002), destacan ese momento de virtualidad en el que el roce de los cuerpos entre sí y con las realidades externas, encerrando todas las posibilidades (todas las respuestas y soluciones potenciales) tiende a ser atrapado por construcciones conceptuales previas (por las rejillas semánticas de las ideologías, dice Massumi). Se trataría del momento más próximo a la experiencia del cuerpo (el más directo, el más visceral) que terminaría cristalizando en una emoción (mitad afecto físico, mitad elaboración intelectual).

Los afectos -observa Massumi- son perspectivas sinestésicas virtuales ancladas en (y funcionalmente limitadas por) la existencia real, las cosas particulares que las encarnan. La autonomía del afecto es su participación en lo virtual. Su autonomía es su apertura. El afecto es autónomo hasta el grado en que escapa de su confinamiento en el cuerpo particular, para el que representa su vitalidad o su potencial de interacción. Las percepciones y cogniciones formadas, calificadas y situadas, que completan funciones de conexión activa o de bloqueo, son la captura y el cierre del afecto. La emoción es la más intensa (la más contraída) expresión de esa captura y del hecho de que de nuevo siempre algo ha vuelto a escapar. (Massumi, 2002, p. 35) ${ }^{2}$

Una vez convertida la afección en emoción, de acuerdo con esta teoría, la conciencia puede comprenderla. No obstante, el concepto nunca puede atrapar la riqueza y complejidad de los afectos (de las impresiones sensitivas) y en ese resto no reconocido (en sus desbordes) podrían encontrarse elementos perturbadores, disociadores de la unidad del concepto y consecuentemente gérmenes del cambio y del dinamismo de los modos de pensar y de sentir de los sujetos. 
En este trabajo se prestará atención a los escenarios emocionales que despliegan las novelas y a esos desbordes resultado de la adhesión de los personajes al paradigma ético revolucionario.

\section{Recorrido rizomático}

En la trilogía sobre los acontecimientos de El Chaparral que inaugura en la región la serie de novelas de guerrilleros, la dimensión emocional de la conversión revolucionaria fue nítidamente captada en el trasfondo de las situaciones. En Trágame tierra (1969) de Lizandro Chávez Alfaro, el personaje Luciano llega a unirse a los revolucionarios como resultado de un enfrentamiento moral con la generación de sus padres que se habían coludido con los caudillos y las compañías fruteras. El papel de las ideas es primordial para este personaje que reconoce el oprobio del país leyendo los libros de historia, si bien el revulsivo más directo lo constituye su padre don Plutarco y sus amigos que rememoran celebratoriamente la edad dorada del imperio del banano y su propia participación en acontecimientos infames. Sin embargo, es en César, el personaje que hace contrapunto a Luciano, en quien puede apreciarse el componente puramente emocional de la revuelta. Sin mediar lecturas e incluso desde la infancia, César es víctima de una emoción humanitaria compulsiva. De niño regalaba todo lo que tenía y cuando llegó a la adolescencia se sintió atraído por La Viqui, un homosexual negro que era objeto de la burla del pueblo. Un día, su padre casi lo mata después de sorprenderlo con un delantal y una escoba barriendo la covacha de La Viqui. Puede apreciarse que al asociar la emocionalidad a la homosexualidad y al valorar la espontaneidad y la naturalidad por encima de la conciencia racional, la novela desafía la vena masculinista y racionalista de la ortodoxia marxista de la lucha. Elementos disociativos que más adelante harían sentir su influjo en la erosión de la empresa revolucionaria.

En Te dio miedo la sangre (1977) de Sergio Ramírez, la fuerza principal que conduce a las rebeliones es sustancialmente emotiva, densificada y extremada por la historia. Los hermanos Rosales que morirán en las incursiones armadas contra la Guardia llegan a ellas como consecuencia espontánea, inevitable de la historia de humillación y desgracia interminables que la dictadura hace padecer a su familia y a su país. Mientras transcurre el caleidoscopio de la historia de Nicaragua, en Guatemala un grupo de exiliados planea amargamente incontables rebeliones $y$, en un bar a las orillas del lago Managua, el trío Los Caballeros canta canciones tristes. La atmósfera fatalista de 
esta novela eleva a la consideración lo que para el narrador pudo ser la forclusión del proyecto revolucionario. La emotividad antidictatorial, la indignación, el odio, han podido inflamarse, acendrarse, incluso corromperse con el paso de los años, pero no han podido canalizarse hacia el auténtico proyecto de lucha armada socialista y antiimperialista. Este proyecto, que para el narrador pudo encerrar la idea iluminadora, es lo forcluido, lo que ni siquiera ha podido ser considerado y la causa del fracaso. Desde este ángulo, la novela podría estar mostrando la inconformidad del letrado y de los cuadros de la vanguardia con los modos de la emotividad tradicional que debían ser desmantelados para dar paso a las emotividades modernas -urgentes, radicales, marxistas- que demandaba el proyecto revolucionario.

En El Valle de las Hamacas (1969) de Manlio Argueta, los personajes son colectivos y el conflicto se presenta como una dialéctica de la violencia, en la que la violencia represiva engendra la revolucionaria, el acoso gubernamental, la radicalización y la guerrilla. Este enfoque resalta la dimensión social del fenómeno, de un sujeto plural que se construye azarosamente traspasado por la influencia de los otros y de factores externos. La opción por la lucha armada surge para los jóvenes personajes en el torbellino de la vida universitaria empujada por los descubrimientos intelectuales y el activismo político. Una vez frente al peligro y la muerte, sin embargo, los personajes tienen miedo. Un intenso subjetivismo, lírico, onírico, afecta a los personajes cuando están en las montañas y se saben en riesgo de ser sorprendidos por el ejército. Los trances más subidos de tono tienen que ver con la nostalgia por la infancia y por el amor a punto de perderse con la vida misma. En términos de Judith Butler, se trataría de una internalización melancólica del objeto amado que en este caso involucraría dimensiones emotivas del yo (el amor, la inocencia) (Butler, 1997, p. 27) que se ven amenazados en los individuos en el momento de su construcción heroica como guerrilleros, derechos a la intimidad, a los sentimientos delicados, al sosiego, a la ternura, a los sueños que entonces pudieron asociarse con debilidades pequeño burguesas por los cuadros y la doctrina militaristas de la empresa, y que han podido reemerger en la literatura en los tiempos de paz de la posguerra.

Judith Butler al considerar el proceso de construcción del sujeto advierte la situación paradójica de que esa construcción dependa de la presión que un poder ejerce sobre el individuo. El sujeto sólo se construye en su adhesión a un poder que le permite reconocerse y visibilizarse. No obstante, esta adhesión tampoco supone una subordinación completa. En los espacios liminales, en los desbordes, el individuo puede 
renovar su proceso de reconoci- tataria pero igualmente disciplinaria miento. El sujeto puede desubjeti- del individuo.

varse y reconstruirse con referencia a otro poder que le permita ejercer su agencia. El poder original podría verse así confrontado por la reacción auto reivindicativa del sujeto sin que, sin embargo, pueda prescindir de un nuevo apego a esa otra forma de poder ahora socialmente contes-

Para Butler es fundamental el reconocimiento de la ambivalencia del sujeto ante el poder que independientemente de su manifestación permanece ejerciendo un influjo represivo:

(...) el sujeto - señala Butler- es él mismo un sitio de esta ambivalencia en la que emerge al mismo tiempo como el efecto de un poder previo y como la condición de posibilidad de una forma de agencia radicalmente condicionada (...)

No hay, por así decirlo, transición conceptual que hacer entre el poder como algo externo al sujeto, que "actúa sobre él", y el poder que constituye al sujeto, "mediante el cual él actúa" (...) El poder actúa sobre el sujeto, una actuación que es un actuar: una ambigüedad irresoluble surge cuando uno intenta distinguir entre el poder que (transitivamente) actúa en el sujeto y el poder actuado por el sujeto, que es entre el poder que forma al sujeto, y el poder "propio" del sujeto (...) Una inversión y un encubrimiento ocurren, en algún momento, y el poder emerge como lo que pertenece exclusivamente al sujeto (haciéndole aparecer como si no hubiera pertenecido a una operación previa de poder). Más aún, lo que es actuado por el sujeto es posible (aunque no del todo determinado) por el trabajo previo del poder. (Butler, 1997, p. 15)

Butler señala que propósitos tituir su agencia, así permanezca no previstos, "propios", pueden condicionada:

emerger en el sujeto para cons-

La agencia excede el poder por el cual ella misma es posible. Uno podría decir que los propósitos del poder no son siempre los propósitos de la agencia. En la medida en que los últimos divergen de los primeros, la agencia es la asunción de un propósito no intencionado del poder, uno que no ha sido derivado lógica o históricamente de sus condiciones previas, que opera en una relación de contingencia y reversión con respecto a ese 
poder que la hace posible como agencia, y al cual sin embargo pertenece. En esto estriba, por así decirlo, la escena ambivalente de la agencia que no se encuentra determinada por necesidad teleológica alguna. (Butler, 1997, p. 15)

Los personajes de las novelas de guerrilleros se encuentran, en efecto, en el complicado momento de la construcción de su agencia. Un paso que es el de jóvenes anodinos de clase media a guerrilleros que supone su emergencia de una subordinación hasta entonces inconsciente a la ideología dominante -que ejercía su poder sobre ellos y los invisibilizaba - a la toma de conciencia de elementos valiosos de su subjetividad - particularmente de su sensibilidad ética humanitaria- pero un reconocimiento que sólo es posible por la adhesión ahora a la ideología revolucionaria que ejercerá un nuevo poder sobre ellos. El proyecto de revolución permite a los individuos ser reconocidos como héroes - una conciencia de sí y una visibilización enormemente gratificantes- pero que va a requerir sacrificios de todo tipo, incluido si es necesario el de la propia vida.

Ejemplo paradigmático de estas novelas quizás lo sea La mujer habitada (1988) de Gioconda Belli en la que se asiste al proceso paulatino de conversión revolucionaria, un proceso que se inicia con roces emocionales con la realidad social y con la toma de conciencia de un legado de feminidad rebelde (que se representa por la guerrera india que habita el inconsciente de la protagonista). Proceso que se profundiza con las lecturas, que cobra el carácter de adhesión programática al movimiento guerrillero con el adoctrinamiento y el entrenamiento militar y que se consuma en la acción armada. Una acción armada, sin embargo, en la que en el mismo momento en que la protagonista da muerte a un oligarca muere ella misma.

Si algo queda claro al leer las novelas de guerrilleros es que el tránsito del roce afectivo con las realidades sociales a la ideología revolucionaria no fue lineal ni carente de tropiezos. Se impone más bien la figura de un tránsito rizomático con ramificados pasajes de ida y vuelta, flujos y reflujos. La impresión que prevalece es la de una emotividad alterada (anárquica y anarquizante) que se encuentra en proceso de ser sometida (estabilizada, normalizada) por el proyecto revolucionario. La conciencia de una sensibilidad lírica (como nostalgia de la individualidad en trance de perderse) permanece, sin embargo, como la evidencia de que no todo ha sido sometido y como la promesa de una insurrección de otro tipo.

No es casual que el clímax de algunas de estas novelas haya sido 
precisamente el de la vacilación. Un momento en el que la determinación de tomar las armas es socavada por sentimientos encontrados. En Una grieta en el agua (1972) de David Escobar Galindo, el grupo de jóvenes queda atrapado en el secuestro ( $y$ en la amenaza de dar muerte a su víctima) que ellos mismos habían fraguado. Si no se paga el rescate ellos deben dar muerte al cautivo, ¿pero cómo serán capaces de hacerlo? En Los demonios salvajes (1978) de Mario Roberto Morales, el protagonista a pesar de un largo aprendizaje en el que se ha conmovido por el sufrimiento de los pobres, en que ha renegado de su condición de clase acomodada y en que se ha llegado convencer de la necesidad de la lucha armada, se acobarda en el último momento. Los miembros de su célula lo emplazan para que participe en una acción armada, pero Walther, el personaje, no se encuentra con valor y se niega a participar. En estas novelas, a diferencia de aquéllas en que se consuma la conversión revolucionaria, la carga emotiva de los personajes excede el poder disciplinario del proyecto revolucionario, el sujeto no acaba de construirse (de hecho se pierde), mientras permanece latente, ambigua, contradictoria, esa emotividad.

\section{Pobrecito poeta que era yo...}

En la novela Pobrecito poeta que era yo... (1971) de Roque Dalton, aparece un personaje que reivindica de forma radical su emotividad autónoma y termina autodestruyéndose. Es Mario, el poeta filósofo y alcohólico que conocemos por las páginas inconclusas de su diario.

La novela en su conjunto es planteada como un rompecabezas existencial. Es un voluminoso collage que presenta la vida de un grupo de escritores en medio de la situación de violencia de El Salvador. Más que contar una historia, la novela busca abrir un espacio de contradicciones entre las distintas opciones vitales, éticas y estéticas de los escritores.
Sus modos de vida, sus actitudes con respecto a la sociedad y sus propósitos literarios los enfrentan entre sí y revelan sus problemas. Particularmente, la novela plantea los conflictos entre la libertad intelectual y las obligaciones morales, entre los intereses del creador y las demandas de la sociedad. El autor ideal, aquel capaz de conciliar plenamente el más ambicioso ejercicio intelectual con el más sincero y concreto compromiso social, no existe. Las virtudes de unos revelan los defectos de otros. De ahí la lamentación del título del libro tomada de un poema de Pedro Geoffroy Rivas por unos poetas que no conseguían superar su condición burguesa. 
El caso de Mario es el de un poeta sumido en las contradicciones entre cristianismo y marxismo. Habiendo sido formado por los jesuitas no ha podido prescindir de la idea de Dios, a pesar de su pretendido ateísmo y de la simpatía que le ha despertado el socialismo. La vocación de poeta es algo no buscado que le vino impuesto como una forma de posesión de su naturaleza y de su carácter. Es "una voz" que lo persigue a todas horas y no lo deja tranquilo. Una voz dice que "no me dejaba vivir y creo que no me habría dejado morir" (Dalton, 1989, p. 227). La poesía ejerce sobre él un efecto comparable al del alcoholismo, es algo que no puede controlar y que lo trastorna. Claramente identifica Mario las emociones como la corriente que lo une al mundo, al sufrimiento humano y a su manifestación en la poesía.

La poesía no es un fin en sí y ni siquiera en otros. La poesía es sólo el vehículo de las emociones y las emociones sólo son uno de los múltiples vehículos para llegar a la suprema verdad. Si esta verdad está emparentada de alguna manera con Dios o con una especie de Dios es cosa que no sé ni mi importa. Porque para los problemas de Dios, es Dios el único competente. Y porque yo no hablo un lenguaje divino sino un lenguaje humano. Un producto humano de las emociones humanas. $Y$ porque se trata de la salvación del hombre y no de la salvación de Dios, que nunca podría haber estado en peligro. Eso es todo y por eso tengo los peores problemas... (Dalton, 1989, p. 228)

El núcleo del conflicto de Mario, como para César -el personaje de Trágame tierra-, es el de una emocionalidad humanitaria compulsiva. No obstante, Mario no experimentará su tragedia de forma enteramente inconsciente como pudo ser el caso de César, sino debatiéndose entre los poderes silenciosos de las ideologías que le reclaman. No pudiendo más ser cristiano, tampoco está dispuesto a acatar como órdenes la axiología revolucionaria. "El compromiso que yo amo - dice- es el más esplendido ejercicio de la libertad" (Dalton, 1989, p. 270). Lector apasionado de Henry
Miller, en ese autor -hijo renegado de la madre del imperialismo- encontrará las modulaciones de lo que llamará una "ética modernamente natural" (Dalton, 1989, p. 272), cuya máxima es obedecer únicamente los dictados espontáneos de su ser: "no hacer ni dar más de lo que me dictara mi capricho" (De Trópico de Capricornio, citado en Dalton, 1989, p. 264). En la práctica sabe que es un hombre frágil: ("Sí, al parecer, soy un dipsómano. Un alcohólico") (Dalton, 1989, p. 327). Es consciente de que su yo es tiranizado por fuerzas superiores ("Me entrego a mí mismo y 
no soy dueño de mí" p. 327). Pero se resiste con todas sus fuerzas a rendir su emocionalidad a forma alguna de autoridad normativa ("Hay en mí un sedimento de auténtica espiritua- lidad que se niega a entorpecerse por nada del mundo" p. 265). Una idea de fidelidad a lo valioso de sí y de resistencia a los poderes externos que se repite a lo largo de su diario:

Hay una lucha sorda que sostengo para, aun ignorando cuál es la realidad del hombre, mantener el fuego del alma constante y permanentemente a salvo de las acechanzas de este mundillo físico. "Los que se quejan me aburren" y "el dolor humano está basado en cálculos deficientes". Sin embargo, la expresión del hombre es la expresión de su dolor... (Dalton, 1989, p. 328)

A diferencia de los otros personajes de la novela, Mario reconoce lo valioso dentro de sí en clave cristiana. El alma no sólo es la capacidad de sentir y pensar sino lo sagrado en el cuerpo, lo que le une a la divinidad. Su conmoción ante el padecer humano es compasión y su búsqueda de expresión a través de la poesía un ruego, un clamor de salvación. Sin embargo, rechaza la religión "porque la religión -dice- es la negación esencial de la moral” (Dalton, 1989, p. 348), esa ética autónoma que ha elegido. Con lo cual viene a ser un cristiano ateo. ("Un cristiano ateizado es el que más creyó en Dios") (p. 344). Una contradicción que tampoco encuentra solución en las demandas de compromiso social. Cuando Roberto, uno de sus amigos sugiere que ingrese al Partido Comunista, Mario reacciona indignado:

(...) Y ha hablado de compromiso, del problema básico de tener o no conciencia sobre lo que está pasando en este país, de la responsabilidad histórica, etc. ¡Qué les parece, qué me parece! ¡Hablarme de compromiso! A mí. A quien de su libertad hizo este caos de peticiones de auxilio, o de emboscadas contra sí mismo, pero que conoce la penitencia de cada paso en falso, de cada cadena que aceptamos o rompemos definitivamente... (Dalton, 1989, p. 321-322)

Más adelante, Mario reconoce que "el hombre es un animal social" $y$ que necesita de una "axiología colectiva" ("la lucha de y por los demás hombres es una parte fundamental de su pragmática" (Dalton, 1989, p. 348). Pero insiste en que sólo puede ser una responsabilidad libremente asumida: si el individuo acepta esa axiología "no debe hacerlo por 
imposición unitaria y por humanística, sino por sí mismo y sólo por sí mismo" (Dalton, 1989, p. 348).

Distingue a Mario de los otros personajes esta conciencia suplementaria de los poderes normativos que le reclaman, lo que concuerda con la representación del momento de cristalización de la agencia, en el que de acuerdo con Butler, el sujeto sólo puede (re)construirse volviendo a rendir algo de su individualidad. La crisis de Mario en parte podría explicarse por la resistencia a esa rendición que le deja en la orfandad de su emotividad autónoma alterada; por este debate entre poderes, por ese impase en el que se niega a ser un humilde cristiano o a hacer entrar en la horma del proyecto revolucionario una emocionalidad que considera trascendente y que desbordándolo convulsiona su cuerpo y disloca su yo.
En el epígrafe del capítulo de Mario, la cita de Henry Miller ("Si el ser no fuera imperecedero, el 'yo' de que escribo se habría destruido hace mucho") establece en un lenguaje profano la conciencia del individuo de participar del ser, de la experiencia humana en su sentido trascendente y en el más craso de una vida terrenal acosada. De modo que al decir del autor norteamericano, por tendencioso que resultara su testimonio ("parcial, rencoroso, malévolo"), lo consideraba parte de esa experiencia con la que los demás iban a tener que habérsela ("es a pesar de todo, la verdad, y tendrán que tragársela"). Exactamente como el diario de Mario, que siendo un documento del yo (marginal aleatorio) inscribe problemas que competen a sus demás amigos poetas tanto como al ser humano.

\section{Escritura emocional}

En declaraciones y pasajes los conflictos emocionales que se sueltos de su obra, Roque Dalton insistió en que su escritura de esos años se orientaba en la dirección de una poética reflexiva. Literatura que dejaba de ser canto - decía- para ser debate de ideas. Unas declaraciones que pudieron ocultar, sin embargo,

encontraban implicados.

En una entrevista de 1969, Dalton expresaba esta reorientación de su trabajo como confrontación con la poesía nerudiana:

Las orientaciones actuales de mi trabajo en la poesía, están encaminadas desde el punto de vista formal a tratar de dejar atrás cierta forma de hacer poesía en América Latina que fue fundada a mi modo de ver por Pablo Neruda, que es la poesía-himno, la poesía-carta, la poesía que se dedica a cantar a las cosas, a los 
hombres, a sus heroísmos (...) nosotros estamos trabajando -un grupo importante de poetas latinoamericanos-en otra dirección: una literatura que en lugar de cantar, plantee problemas, plantee conflictos, plantee las ideas, que son muchísimo más eficaces que los himnos para hacer que el hombre cobre conciencia de sus problemas en la lucha de liberación de nuestros pueblos, por ejemplo. Esto desde el punto de vista formal. Y desde el punto de vista ideológico, también insistir mucho en el matiz de la contradicción (...) El no dar soluciones hechas, no dar poemas donde no existan contradicciones de fondo, sino, por el contrario, ofrecer la posibilidad al lector de que se integre a la mecánica en el proceso de desarrollo, con la ideología poéticamente expresada. (Dalton, 1986a, Entrevista, p. 15).

En un doble movimiento, Dalton exaltaba la poesía de ideas y execraba la de emociones, en un gesto que podría considerarse típicamente moderno y machista. La racionalidad como fuerza del progreso humano y característicamente masculina, a su juicio, habría de hacer de la poesía algo más productivo para las luchas de liberación que la emocionalidad, más bien femenina, pasiva e impráctica. Si bien la situación pudo ser lo contrario: la de la represión de una emocionalidad que se sobreponía a la racionalidad.

En unas declaraciones anteriores de 1966, refiriéndose al mismo asunto de las contradicciones como génesis dialéctica de la poesía, Dalton habló de ellas como "desgarraduras", esto es, como heridas, con lo cual puso de manifiesto que los debates de ideas no ocurrían en el vacío sino en un cuerpo que sufría con ellas.

He tenido conflicto (entre militancia y escritura) cuando he tenido problemas ideológicos. Cada vez que he experimentado una desgarradura, ha sido porque se me planteaba una contradicción entre una posición política y una posición ideológica expresada en la literatura. En la medida en que pude superar mis debilidades en este terreno, di pasos hacia delante, en la medida en que no los pude superar tengo aún conflictos. (Dalton, 1986b, La vida escogida, pp. 54-55).

Si como se dejó anotado antes, las reacciones emotivas no son independientes de las intelectuales, si la emoción existe ligada a la idea que la hace inteligible, entonces, debatirse entre emociones supone debatirse entre ideas y probablemente con frecuencia al contrario. Dos 
caras de un mismo drama con el que aquí Dalton se autorepresentaba; un poeta sumido en contradicciones como los personajes de su novela.

De este modo, la reorientación de la poesía de Dalton pudo no estar dirigida simplemente al debate ideológico sino al espacio contradictorio de las emociones, ese espacio de virtualidad y potencialidad en el que una emoción puede dar la razón a una idea y otra negársela y cada vuelco tensionar al poeta. Su escritura pudo estarse orientando a una exploración emocional de este tipo que conduciría a sus poemasproblema y a su novela-problema de esos años.

Como Dalton, Mario su personaje, también planea escribir una novela, la que en un momento concibe como puramente reflexiva y en otro como puramente emotiva. Dice Mario:

\begin{abstract}
Mi novela debe ser irritante y catártica. Buscando esa fiebre intensa, provocada por el grito del curandero que sacara los males del cuerpo, por el sudor y la orina, y los del alma por la desesperación.
\end{abstract}

Nada de máscaras ni emboscadas para una clientela de lectores torpes. Por el contrario: paciente raciocinio y dureza. Sobre todo dureza. Una novela debe ser como un límpido diamante. Resultado, en fin, de presiones seculares en que los diversos estratos del cuerpo y del alma han acabado por pulimentarlo todo... (Dalton, 1989, p. 249)

Una es una novela que nace del cuerpo y del alma, de sus excrecencias y humores, de sus contorsiones y espasmos, mientras que la otra es el resultado de una dura racionalidad que comprime la experiencia. Pobrecito poeta que era yo..., si bien consiguió plantear una problemática existencial, resulta a todas luces mucho más emocional que racional. Novela tormentosa, en efecto catártica, de perfiles mal definidos y de un lenguaje heteróclito que arrastra por igual lo humano y lo divino, lo noble y lo abyecto.
Para Ileana Rodríguez, el lenguaje roto y deslavazado de esta novela es indicio de la búsqueda personalista de expresión: “(...) un sintagma quebrado, violado en su totalidad y en sus partes parece ser la mejor expresión del esfuerzo por parir un texto auténtico y coyuntural (...)" (Rodríguez, 1986, p. 373).

Igualmente, Ileana Rodríguez reconoce como distintivo de esta novela su desmesura, el exceso de expresión, de realismo: "Dalton busca $y$ encuentra el efecto: atiborra el 
espacio hasta hacerlo intransitable, Orgambide, "trabaja con una libertad sobrecarga sin descanso ni tregua; absoluta”, pero "paradójicamente es abundoso hasta lo irrespirable en esta extrema libertad debilita a la adjetivación (...)" (Rodríguez, 1986, nuestro entender, la totalidad de p. 375).

Pedro Orgambide sostuvo que la cualidad más valiosa de Pobrecito poeta quizá fuera justamente la de ser una mala novela. Dalton, dice

la novela, difícil de visualizar como estructura orgánica" (Orgambide, 1986, p. 365-366). En cierto sentido, para Orgambide la novela de Dalton es una antinovela en busca de una forma incierta:

La novela, ese mismo producto del humanismo burgués, se cuestiona, se atomiza, se niega, se destruye para volver a emerger con una nueva calidad (...). Este libro es testimonio de esa lucha. Ciertas técnicas, como la utilización del collage, dan pruebas de esa lucha entre lo externo y lo interno de la narración; una lucha sin definir aún, un campo de nadie que el narrador utiliza para resolver como puede ese conflicto que está en su propia escritura... (Orgambide, 1986, p. 368)

\section{Autodestrucción}

Martha Nussbaum propone reconocer un sentido intrínsecamente democrático en la emoción trágica en tanto resulta del reconocimiento de la fragilidad de los seres humanos y de su universal necesidad de los bienes de la vida:
La expectación trágica cultiva la conciencia emocional de las posibilidades humanas compartidas, enraizadas en la vulnerabilidad del cuerpo... (Nussbaum, 2013, p. 258)

(...) tragedias como éstas promueven una visión emocional que conecta a la gente a la realidad, no sólo de su propio sufrimiento sino del de los demás... (p. 261)

(...) promueve una experiencia que es en el mejor sentido democrática, que reconoce la igual fragilidad de todos los seres humanos y su plenamente igual necesidad de los bienes de la vida... (p. 263) $)^{5}$ 
Para Martha Nussbaum, la emoción trágica supone la conciencia de la vulnerabilidad humana y hace posible extender la preocupación por los demás más allá del círculo inmediato o del grupo dominante. De acuerdo con su definición, esta emoción se corresponde con la compasión, con la conciencia de un sufrimiento grave infligido sobre las personas, un sufrimiento que ocurre o podría ocurrir a cualquiera y con la conciencia del espectador de una condición compartida con los que sufren (Nussbaum, 2013, p. 261-262).
Mario manifiesta esa inclinación que puede considerarse democrática de la emoción trágica cuando dice amar como los niños. "Yo soy distinto. Yo amo antes que nada. Todo lo amo. Todo lo amo." (Dalton, 1989, p. 336). Pero se contradice cuando al mismo tiempo reconoce albergar el odio, cuando incluso se reclama a sí mismo por no odiar todo cuanto debería, refiriéndose sin duda a lo que es causa de dolor (la injusticia, la opresión, la muerte, entre otros).

Todo lo amo, es cierto. Pero lo amo porque ya no tengo fuerza suficiente para odiar todas las cosas que debería. Y en el fondo, porque las odio, es que voy y voy ataráxico y enmierdado. (Dalton, 1989, p. 336)

En la dirección de los planteamientos de Martha Nussbaum, el amor sería funcional a la convivencia social armónica, pero Mario ama y odia con lo cual confronta simultáneamente el orden social. Si el amor por los demás podría suscribirse al cristianismo y al credo democrático liberal, el odio podría hacerlo al marxismo y a la lucha de clases, los polos ideológicos entre los que podría estarse debatiendo el personaje. Contrario a la idea de la coherencia y la estabilidad de la emoción trágica, que podría desprenderse de los planteamientos de la autora, el personaje de Dalton estaría exhibiendo el carácter neurótico, contradictorio y del todo imprevisible de esa emoción.

Mario viene a ser un conflictuado espectador trágico en el que se reconocen ciertas notas metafísicas de su drama. Más allá de las situaciones prácticas, le sensibilizan las trascendentes: la condición humana. En los poemas que consigna en su diario, el dolor del que habla puede ser entendido como una conciencia del ser y del destino humanos, carne y espíritu arrojados al sufrimiento. 
(...) a veces, en la pausa de una piedra a la vera del desierto, se oye susurrar el viento alborotando las estrellas.

Y la agonía de un hombre solo camina ancha y errabunda en

en medio de la noche estentórea medio de los pastizales,

tan llena de murciélagos y de esperanzas muertas... (Dalton, 1989, p. 230)

En el paisaje onírico del sufrimiento, parece decir el poema, un individuo padece el dolor de todos. Un padecimiento que como en la poesía de César Vallejo es una interrogación por el sentido. Por otro poema puede inferirse que ese indi- viduo y esa preocupación son imposibles porque la conciencia de las cosas será siempre limitada y porque la vida transcurre en el tiempo ordinario donde no hay cabida para experiencias de esta naturaleza:

\section{(...) Y a la pregunta que inquiere por la solidez de los cimientos todo se esfuma, porque el ritmo loco del mundo no resiste la mínima duda y porque uno debe morir sobre la marcha, como los peces. ("Salto al vacio"), (Dalton, 1989, p. 262)}

Podría decirse que en Mario la emocionalidad humanitaria es experimentada en su forma más extrema, en lucha contra las ideologías y haciéndose cargo del sufrimiento universal. Una especie de emocionalidad pura que acogiera el padecer humano en toda su extensión, multiplicidad e intensidad. Algo sin duda superior a las fuerzas de las personas de carne y hueso. Un proyecto de experiencia subjetiva absolutamente descabellado que el personaje, efectivamente, no podrá soportar.

Cuando una ola represiva, seguida de un golpe de Estado, abata la sociedad y sus amigos más cercanos caigan presos en peligro de muerte,
Mario recaerá gravemente en su alcoholismo y morirá apuñalado en oscuras circunstancias.

Esta muerte puede considerarse una autodestrucción por cuanto se asocia al proyecto deliberado de una sensibilidad autónoma para la que el mismo personaje reconocía carecer de la entereza que le demandaba. De forma refractaria su resistencia a someterse a las ideologías revela el efecto benévolo que las mismas pueden tener para los individuos. Negándose a hacer comprensibles, manejables y consecuentemente a domesticar sus emociones bajo el encuadramiento del cristianismo o del marxismo, el personaje resiste su 
dominación pero al mismo tiempo se niega la función estabilizadora que habrían podido proveerle.
Sin amparo apaciguador y en un acuciante contexto, el personaje se destruye.

\section{Conclusiones}

Las novelas de guerrilleros muestran de qué manera la escritura literaria pudo ser entendida en este momento como una exploración emocional. La emocionalidad misma pudo concebirse como una activación y una toma de conciencia de las potencialidades de los individuos, mientras que su cristalización ética pudo suponer un encauzamiento de esa emocionalidad, su estabilización y normalización bajo la autoridad de un proyecto práctico. Como en la filosofía clásica, las emociones se muestran como reacciones a flor de piel, fáciles y volubles, mientras la razón se presenta como la autoridad capaz de darles coherencia, sentido y durabilidad.

El caso del personaje de la novela de Dalton ilustra la experiencia emocional en el momento de ser reclamada por el compromiso. Puede apreciarse la crisis del individuo como consecuencia de su emocionalidad humanitaria (como en las demás novelas de guerrilleros) y, especialmente, puede apreciarse el debate de ese individuo entre los poderes ideológicos que reclaman su emocionalidad. A pesar de los propósitos del personaje de preservar la autonomía de sus emociones, en su muerte parece cumplirse la afirmación de Judith Butler de que el sujeto requiere de la adhesión a un poder para poder construirse. De la novela se desprende la idea de que la emocionalidad pura e ilimitada puede ser una forma de autodestrucción.

No suficientemente destacado hasta ahora quizá sea el hecho de que el compromiso revolucionario suponía, en este momento, el compromiso con la lucha armada y consecuentemente el sacrificio anticipado de la vida. Dalton iba a ser uno de los exponentes preclaros de este radicalismo que lo conduciría a él mismo a la muerte, aunque como se sabe por sus propios compañeros de armas. Probablemente, las novelas de guerrilleros no habrían mostrado su distintiva hipersensibilidad si en el trasfondo no se hubiera encontrado este reclamo de las vidas de los jóvenes. De todo interés es ese desborde emocional registrado en las novelas que demuestra hasta qué punto las sensibilidades rebasaron el proyecto revolucionario y cuánto debieron ser sometidas para hacerlo realidad. 


\section{Referencias}

- Argueta, M. (1976). El valle de las hamacas. (2 edición). San José, Costa Rica: EDUCA.

- Belli,G.(1988).La mujer habitada. Managua,Nicaragua:Editorial Vanguardia.

- Butler, J. (1997). The Psychic Life of Power: Theories in Subjection. Palo Alto, California: Standford University Press.

- Chávez Alfaro, L. (1989). Trágame tierra. México: Editorial Diógenes.

- Dalton, R. (1986a). Entrevista a Carlos Otero. (1969). En H. García Verzi (Comp.) "Prólogo" a Recopilación de textos sobre Roque Dalton. Pp. 7-16. La Habana: Centro de Investigaciones Literarias, Casa de las Américas.

- (1986b). La vida escogida. En H. García Verzi (Comp.) Recopilación de textos sobre Roque Dalton. Pp. 35-63. La Habana: Centro de Investigaciones Literarias, Casa de las Américas.

. (1989). Pobrecito poeta que era yo.... ( $4^{\circ}$ edición). San José, Costa Rica: EDUCA.

- Escobar Galindo, D. Una grieta en el agua. (1971). (Segundo Premio Centroamericano de Novela Breve "Rafael Osejo"). San José, Costa Rica: S. E.

- García Verzi, H. (Comp.). (1986). Recopilación de textos sobre Roque Dalton. La Habana: Centro de Investigaciones Literarias, Casa de las Américas.

- Leyva, H. M. (1996). Narrativa de los procesos revolucionarios centroamericanos (1960-1990). Universidad Complutense de Madrid. (Tesis doctoral). Consultado en: www.ucm.es/BUCM/tesis/19911996/H/3/AH3024501.pdf

(s. f.). "Narrativa de los procesos revolucionarios centroamericanos (1960-1990)". Ensayo inédito para Literatura e intervención política, $4^{\circ}$ volumen de la serie: Hacia una Historia de las Literaturas Centroamericanas, (en proceso de edición y publicación por la Editorial $F \& G$ de Guatemala).

- Massumi, B. (2002). Parables of the Virtual. Movement, Affect, Sensation. Durham \& London: Duke University Press.

- Morales, M. R. (1978). Los demonios salvajes. Guatemala: Departamento de Publicaciones de la Dirección General de Cultura y Bellas Artes.

- Nussbaum, M. C. (2013). Political Emotions. Why Love Matters for Justice. Cambridge/ London: The Belknap Press of Harvard University Press.

- Orgambide, P. (1986). La novela como pretexto. En H. García Verzi (Comp.). Recopilación de textos sobre Roque Dalton. Pp. 364-372. La Habana: Centro de Investigaciones Literarias, Casa de las Américas. 
- Ramírez, S. (1983). ¿Te dio miedo la sangre? Barcelona, España: Editorial Argos.

- Rodríguez, I. (1986). El texto literario como expresión mestizo creole. In memoriam. En H. García Verzi, (Comp.). Recopilación de textos sobre Roque Dalton. Pp. 370-375. La Habana: Centro de Investigaciones Literarias, Casa de las Américas.

\section{Notas}

1 Ensayo presentado en el Congreso de la Latin American Studies Association, San Juan, Puerto Rico, 27 al 30 de mayo de 2015.

2 "Affects are virtual synesthetic perspectives anchored in (functionally limited by) the actually existing, particular things that embody them. The autonomy of affect is its participation in the virtual. Its autonomy is its openness. Affect is autonomous to the degree to which it escapes confinement in the particular body whose vitality, or potential for interaction, it is. Formed, qualified, situated perceptions and cognitions fulfilling functions of actual connection or blockage are the capture and closure of affect. Emotion is the most intense (most contracted) expression of that capture and of the fact that something has always and again escaped" (Massumi, 2002, p. 35).

3 "(...) the subject is itself a site of this ambivalence in which the subject emerges both as the effect of a prior power and as the condition of possibility for a radically conditioned form of agency (...)

“There is, as it were, no conceptual transition to be made between power as external to the subject, 'acting on', and power as constitutive of the subject, 'acted by' (...) Power acts on the subject, an acting that is an enacting: an irresolvable ambiguity arises when one attempts to distinguish between the power that (transitively) enacts the subject, and the power enacted by the subject, that is, between the power that forms the subject, and the subject's 'own' power (...) At some point, a reversal and concealment occurs, and power emerges as what belongs exclusively to the subject (making the subject appear as if it belonged to no prior operation of power). Moreover, what is enacted by the subject is enabled but not finally constrained by the prior working of power" (Butler, 1997).

4 "Agency exceedes the power by which it is enabled. One might say that the purposes of power are not always the purposes of agency. To the extent that the latter diverge from the former, agency is the assumption of a purpose unintended by power, one that could not have been derived logically or historically, that operates in a relation of contingency and reversal to the power that makes it posible, to which it nevertheless belongs. This is, as it were, the ambivalent scene of agency, constrained by no teleological necessity" (Butler, 1997, p. 15).

5 "Tragic spectatorship cultivates emotional awareness of shared human possibilities, rooted in bodily vulnerability (...)" (Nussbaum, 2013, p. 258).

"...tragedies such as these promote an emotional insight that connects people to the reality not only of what their own side is suffering but also of what they are doing to others (...)" (p. 261).

"...it promotes an experience that is in the best sense democratic, one that acknowledges the equal frailty of all human beings and their fully equal need for the goods of life (...)" (p. 263). 